\title{
Enigmas of primary immunodeficiency and mycobacterial infection in our territory
}

Roya Sherkat

From Canadian Society of Allergy and Clinical Immunology Annual Scientific Meeting 2013

Toronto, Canada. 3-6 October 2013

\section{Introduction}

Defects of the immune system in Primary immunodeficient diseases (PIDs) predispose individuals to recurrent infections. Complex genetic components for susceptibility to mycobacterial disease have been suggested. Natural human immunity to the mycobacteria group, including Mycobacterium tuberculosis(MTB), Bacille Calmette-Guérin (BCG) or nontuberculous mycobacteria (NTM) relies on the functional IL-12/23-IFN- $\gamma$ integrity of macrophages (monocyte/dendritic cell) connecting to $\mathrm{T}$ lymphocyte/NK cells [1]. Restricted defective molecules in the circuit and recently discovered CYBB responsible for autophagocytic vacuole and proteolysis have been identified in around $60 \%$ of patients with the Mendelian susceptibility to the mycobacterial disease (MSMD) phenotype [2].

Primary defects in oxidase activity in chronic granulomatous disease (CGD) lead to severe, life-threatening infections. The role of phagocytic respiratory burst in host defense against mycobacterium tuberculosis was controversial. Previous studied showed that the critical role at reactive oxidants is to serve as intracellular signals for activation of microbicidal enzymes, rather than excretions a microbicidal effect perse [3]. The role of phagocytic respiratory burst in host defense against $M$. TB is further supported by recent studies discovered immunological defects secondarily affecting phagocyte respiratory burst function and resulting in primary immunodeficiencies with varied phenotypes, including susceptibilities to pyogenic or mycobacterial infections [4].

The patients with severe PID's like SCID have broader diverse infections susceptibility and mycobacterial infections as well, however, Common variable

Correspondence: sherkat@med.mui.ac.ir

Acquired Immunodeficiency Research Center, Isfahan University of Medical Sciences, Isfahan, Iran immunodeficiency (CVID) mostly characterized by a deficiency of immunoglobulins and recurrent sinopulmonary infections.

\section{Method}

We overview the clinical rate of mycobacterial disease in our PID cases and evaluate the complex cases.

\section{Results}

Two hundred PID cases were evaluate between 1996-2013 in our clinic, Among 5\% of them which diagnosed as MSMD nearly all presented with mycobacterial infection. $8 \%$ diagnosed as CGD and interestingly $60 \%$ of them have been experienced mycobacterial disease sometimes in their life, as disseminated BCG or late onset complications of BCG including osteomyelitis or MTB once or more than one episode through their life. Also we have presented a CVID patient with disseminated TB and granulomatouse hepatitis, TB arthritis and peritonitis.

\section{Conclusion}

PID cases Like CGD, MSMD or CVID which are living in area's with high prevalence of mycobacterial infection could have quiet different presentations and the study of these complex cases has provided essential insights into the functioning of the immune system. Despite the conventional view we have confirmed that the generation of ROIS by phagocytic respiratory burst may play a role in the defense of the host against $M$. tuberculosis by clinical evidence.

\section{Published: 3 March 2014}

\section{References}

1. Salem $S$, Gros P: Genetic determinants of susceptibility to Mycobacterial infections: IRF8, a new kid on the block. Adv Exp Med Biol 2013, 783:45-80,

2. Lee WI, Huang JL, Yeh KW, Jaing TH, Lin TY, Huang YC, Chiu CH: Immune defects in active mycobacterial diseases in patients with primary 
immunodeficiency diseases (PIDs). J Formos Med Assoc 2011,

110(12):750-8.

3. Reeves EP, Lu H, Jacobs $\mathrm{HL}$, et al: Killing activity of neutrophils is mediated through activation of proteases by $\mathrm{K}+$ flux. Nature 2002, 416:291-7.

4. De Oliveira-Junior EB, Bustamante J, Newburger PE, Condino-Neto A: The human NADPH oxidase: primary and secondary defects impairing the respiratory burst function and the microbicidal ability of phagocytes. Scandinavian Journal of Immunology 2011, 73(5):420-427.

doi:10.1186/1710-1492-10-S1-A30

Cite this article as: Sherkat: Enigmas of primary immunodeficiency and mycobacterial infection in our territory. Allergy, Asthma \& Clinical

Immunology 2014 10(Suppl 1):A30.

\section{Submit your next manuscript to BioMed Central} and take full advantage of:

- Convenient online submission

- Thorough peer review

- No space constraints or color figure charges

- Immediate publication on acceptance

- Inclusion in PubMed, CAS, Scopus and Google Scholar

- Research which is freely available for redistribution

Submit your manuscript at www.biomedcentral.com/submit 